\title{
Evaluation of Maritime Transport Support Mode for Islands and Reefs Based on DEA
}

\author{
Huang Jiashuai ${ }^{1, a}$, Dong Peng ${ }^{2, b}$, CaiYi $^{3}$ \\ ${ }^{1}$ Department of management engineering and equipment economics, Naval University of Engineering, Wuhan, China \\ ${ }^{2}$ Department of management engineering and equipment economics, Naval University of Engineering, Wuhan, China \\ ${ }^{3}$ Teaching and research support center, Air Force Early Warnming Academy, Wuhan, China
}

\begin{abstract}
On the basis of the analysis and summary of several maritime transport support modes for the material replenishment of islands and reef, a DEA model is established in this study to calculate the relative validity of the above-mentioned modes by solving the linear programming question. Consequently, the support modes can be sorted by the validity value. Finally, impact factors can be located and improvements can be made through eliminating the variables, leading to potential room for maritime transport support optimization.
\end{abstract}

\section{Introduction}

Due to the special geographical environment and natural conditions of the islands and reefs, transport of goods to the islands has always been the biggest problem. For a long time, transportation departments at all levels actively have implemented the instructions of the superior, actively explored and innovated, and adopted many effective maritime transport support models, which basically meet the living needs of the personnel on the island and reefs, but there are still problems in the efficiency and effectiveness of supplies. Therefore, the scientific and accurate comprehensive evaluation and optimization of various transport support modes is of great practical significance for the rational use of limited resources, the efficient completion of replenishment missions, and the improvement of defense capability of far-sea islands and reefs.

\section{Analysis on the Mode of Maritime Transport Support for Islands and Reefs}

At present, there are mainly three modes of maritime transport support for material replenishment of islands and reefs:

Mode 1, each unit transports separately. The civil living materials shall be transported by the public service ship or by the ships of Waters Guard District instead to support the local personnel; the materials of the garrison troops are transported by ships under the jurisdiction of each military branch. In general, the units are independent from each other and coordinate with each other to carry out partial forwarding when there are special needs.

Mode 2, joint logistic support. After summarizing the demand data of each unit, the joint service support department plans to allocate the transport capacity, and then appoints a responsible unit for unified supply. This mode can not only reduce the cost and save transport capacity, but also improve supply efficiency to a large extent. However, the approval process is complicated.

Mode 3, civil-military integrated. When the conditions permits, civil or commercial vessels shall be used to carry out the transportation of some subsistence goods, and jointly complete the Replenishment task with the vessels in the government and military establishment. This mode can make full use of social resources, reduce the pressure on the troops, and enable the troops to focus more on the improvement of the core fighting capacity, but there is a lack of standardization in the collaborative process.

The above three maritime transport support modes are the crystallization of more than a decade of military transport work, with different characteristics (as shown in Table 1). 
TABLE 1.COMPARATIVE ANALYSIS OF DIFFERENT SUPPORT MODES.

\begin{tabular}{|c|c|c|}
\hline Support Mode & advantages & disadvantages \\
\hline Separate Support & $\begin{array}{c}\text { The relationship is clear and the } \\
\text { procedure is simple }\end{array}$ & $\begin{array}{c}\text { Replenishment may not be timely, } \\
\text { the unloaded ratio of ships is high }\end{array}$ \\
\hline $\begin{array}{c}\text { Joint Logistic } \\
\text { Support }\end{array}$ & $\begin{array}{c}\text { The resources are allocated optimally, the } \\
\text { transportation capacity and expenses are } \\
\text { saved, and the transportation efficiency is } \\
\text { high }\end{array}$ & $\begin{array}{c}\text { The application and approval } \\
\text { procedures are complicated and } \\
\text { the rules and regulations are not } \\
\text { sound enough }\end{array}$ \\
\hline $\begin{array}{c}\text { Civil-military } \\
\text { Integrated Support }\end{array}$ & $\begin{array}{c}\text { Saving the resources of the army,the } \\
\text { transportation equipment and technology } \\
\text { are more advanced }\end{array}$ & $\begin{array}{c}\text { Coordination is difficult and there } \\
\text { are many unsafe factors in local } \\
\text { vessels. Uncontrollability of the } \\
\text { freight contractor }\end{array}$ \\
\hline
\end{tabular}

\section{Establishment of evaluation model}

\subsection{Model Selection}

To judge the advantages and disadvantages, we should evaluate the support effect of above three modes. However, there are so many factors that affect the guarantee effect that it is difficult to enumerate them all and assign them scientifically. Therefore, this paper adopts DEA (Data Envelopment Analysis), which is suitable for evaluating the relative merits of multiple similar systems.Based on the relative concept, it is a systematic analysis method to evaluate the relative effectiveness of the same type of units according to the multi-index input and multi-index output,and its advantages are mainly reflected in the following points:

a) Taking the weight of the input and output of the decision-making unit as a variable, the evaluation is made from the perspective of the most beneficial to the decision-making unit, so as to avoid determining the weight of each index in the priority sense [1];

$b$ )There is no need to determine the display expression of the relationship between the input and output metrics;

c) Without any weight assumption, it has strong objectivity.

Through this method, multiple decision-making units of the same type can be evaluated, sorted and improved

\subsection{Modelling}

1)Determination of DMU. The DMU set refers to a series of system units with the same target task, the same external environment and the same input and output indexes [2].Here, a DMU is a maritime transport support mode, performing the same support task under a similar background, with the same resource type of "input" and the same measurement index of "output".

2) Determination of input and output indicators. The input of the DMU are the resources invested in the task, these resources should be classified and the indicators to measure these "inputs" should be determined. According to the execution process of transport and replenishment missions, the factors that affect the effect of transport support can be summarized into resource allocation capacity, transport capacity, transport command capacity and handling capacity[3], based on which the input index can be analyzed.

Among them, the resource allocation capacity mainly includesfour aspects: human resources, transportation equipment, support accessories, and materials raising. Personnel are the principal part of the task, and their professional skill level, in-work rate and the utilization rate all have great influence on the task completion effect, the fill rate of demand for transportation equipment and accessories determines the mode and efficiency of task execution; time of materials raising is an intuitive index to measure the time cost invested.

The level of transport capacity can reflect the amount of resources invested in transportation equipment, which is affected by such factors as set-up time of vehicles, number of ships and average transport capacity of vehicles. Command ability is influenced by environmental situation, mission strength and the quality of commander. Handling capacity reflects the amount of resources invested in loading and unloading equipment, and its influencing factors include the amount of loading and unloading equipment, utilization rate of loading and unloading equipment, etc.

The output of the DMU is the benefit generated by utilizing the resources invested, here refers to the effect of the replenishment mission. Supplementary rate of inventory replenishment rate and intact rate of materials can reflect the intuitive effect and direct benefit of completing the replenishment mission, the recovery rate of combat capability is a measure of the quality of the replenishment mission completed.

According to the purpose of evaluation and the actual situation, representative parameters with good availability were selected from the above index factors, and the input and output parameters of the model were determined as shown in Table 2:

TABLE 2.INPUT AND OUTPUT INDICATORS OF DMU.

\begin{tabular}{|l|l|}
\hline \multicolumn{1}{|c|}{ Input parameter $(x)$} & Ouput parameter $(y)$ \\
\hline $\begin{array}{l}\text { Utilization rate of } \\
\text { personnel }\left(x_{1}\right)\end{array}$ & $\begin{array}{l}\text { Supplementary rate of } \\
\text { inventory }\left(y_{1}\right)\end{array}$ \\
\hline $\begin{array}{l}\text { Fill rate of transportation } \\
\text { equipment }\left(x_{2}\right)\end{array}$ & $\begin{array}{l}\text { Intact rate of } \\
\text { materials }\left(y_{2}\right)\end{array}$ \\
\hline $\begin{array}{l}\text { Fill rate of } \\
\text { supportaccessories }\left(x_{3}\right)\end{array}$ & $\begin{array}{l}\text { Recovery rate of } \\
\text { combat capability }\left(y_{3}\right)\end{array}$ \\
\hline
\end{tabular}




\begin{tabular}{|l|l|}
\hline $\begin{array}{l}\text { Time of materials } \\
\text { raising }\left(x_{4}\right)\end{array}$ & \\
\hline Number of $\operatorname{ships}\left(x_{5}\right)$ & \\
\hline $\begin{array}{l}\text { Number of handling } \\
\text { equipment }\left(x_{6}\right)\end{array}$ & \\
\hline
\end{tabular}

3) Establishment of DEA model. Suppose there are $n$ $\operatorname{DMUj}(1 \leq j \leq n)$, and each DMU has $m$ input variables and $n$ output variables, that is, the corresponding input and output vectors of DMUj are expressed as follows:

$$
\begin{aligned}
& x_{j}=\left(x_{1 j}, x_{2 j}, \cdots, x_{m j}\right)^{\mathrm{T}}>0, \quad j=1,2, \cdots, n \\
& y_{j}=\left(y_{1 j}, y_{2 j}, \cdots, y_{s j}\right)^{\mathrm{T}}>0, \quad j=1,2, \cdots, n \\
& x_{i j}>0, \quad y_{r j}>0, \quad i=1,2, \cdots, m ; \quad r=1,2, \cdots, s
\end{aligned}
$$

Constructing the linear programming model as follows:

$$
\text { s.t. }\left\{\begin{array}{c}
\min \theta \\
\sum_{j=1}^{n} \lambda_{j} x_{j} \leq \theta x_{j 0} \\
\sum_{j=1}^{n} \lambda_{j} y_{j} \geq y_{j 0} \\
\lambda_{j} \geq 0, \quad j=1,2, \cdots, n
\end{array}\right.
$$

In the above model: $\lambda_{j}(j=1,2, \cdots, n)$ is the combined weight of $n$ DMUs; $x_{j 0}$ and $y_{j 0}$ are the input and output vectors of the $j_{0}$ th DMU; $\theta(\leq 1)$ is the effective value of DEA.

This is the $\mathrm{C}^{2} \mathrm{R}$ model. The effectiveness (efficiency) of the $j_{0}$ th DMU relative to other units can be obtained without preset parameter weight by solving it. Based on these effective values we can sort several DMUs. However, when the efficiency value of multiple DMU is all 1 , the $C^{2} \mathrm{R}$ model cannot be used for further evaluation, so the Super-efficiency model needs to be introduced, of which the basic idea is to extract the effective DMU from the reference set and calculate its super efficiency score. By introducing two slack variables $s_{i}{ }^{-}(i=1,2, \cdots, m), s_{r}{ }^{+}(r=1,2, \cdots, s)$ and the non-Archimedes infinitesimal $\varepsilon$, the following linear program is constructed [4]:

$$
\begin{aligned}
& \min \left[\theta-\varepsilon\left(\sum_{i=1}^{m} s_{i}{ }^{-}+\sum_{r=1}^{s} s_{r}{ }^{+}\right)\right] \\
& \text {s.t. }\left\{\begin{array}{l}
\sum_{j=1, \neq j 0}^{n} \lambda_{j} x_{j}+s_{i}{ }^{-}=\theta x_{j 0} \\
\sum_{j=1, \neq j 0}^{n} \lambda_{j} y_{j}-s_{r}{ }^{+}=y_{j 0} \\
\lambda_{j} \geq 0, \quad j=1,2, \cdots, n \\
s_{i}{ }^{-} \geq 0, \quad s_{r}{ }^{+} \geq 0
\end{array}\right.
\end{aligned}
$$

The super-efficiency model allows the efficiency value $\theta$ to exceed 1, which can be used to further prioritize the units that cannot be compared under the $\mathrm{C}^{2} \mathrm{R}$ model.

\section{Model calculation and result analysis}

\subsection{Data collection}

After processing the original data, the input and output data as shown in Table 3 are obtained, in which the $\mathrm{DMU}_{1}$ represents Mode 1(each unit transports separately), the $\mathrm{DMU}_{2}$ represents Mode 2(joint logistic support), the $\mathrm{DMU}_{3}$ represents Mode 3(civil-military integrated).

Among them, utilization rate of personnel $\left(x_{1}\right)$, fill rate of transportation equipment $\left(x_{2}\right)$, fill rate of support accessories $\left(x_{3}\right)$, time of materials raising $\left(x_{4}\right)$, number of $\operatorname{ships}\left(x_{5}\right)$, number of handling equipment $\left(x_{6}\right)$, supplementary rate of inventory $\left(y_{1}\right)$ and intact rate of materials $\left(y_{2}\right)$ are quantitative indicators, which can be obtained by summarizing the actual situation.The recovery rate of combat capability $\left(y_{3}\right)$ is a qualitative indicator,which needs to be quantified. We invited 6 experts and scholars with rich experience in transportation and replenishment of islands and reefs and transportation delivery departments to score the completion effect of a replenishment mission under three modes (on a 10-point scale) and estimate the variance of the score (allowable error $\delta \leq 0.001$ ), if the variance is greater than 0.001 , score again until $\delta \leq 0.001$, thus obtaining the quantitative value of combat capability improvement rat.

\section{TABLE 3.INPUT AND OUTPUT DATA OF EACH SUPPORT} MODE.

\begin{tabular}{|c|c|c|c|}
\hline Indicators & $\mathbf{D M U}_{\mathbf{1}}$ & $\mathbf{D M U}_{\mathbf{2}}$ & $\mathbf{D M U}_{\mathbf{3}}$ \\
\hline$x_{1}$ & 0.95 & 0.77 & 0.87 \\
\hline$x_{2}$ & 0.78 & 0.60 & 0.80 \\
\hline$x_{3}$ & 0.69 & 0.68 & 0.75 \\
\hline$x_{4}$ & 50 & 43 & 38 \\
\hline$x_{5}$ & 8 & 10 & 6 \\
\hline$x_{6}$ & 30 & 25 & 23 \\
\hline$y_{1}$ & 0.76 & 0.88 & 0.90 \\
\hline$y_{2}$ & 0.90 & 0.93 & 0.96 \\
\hline$y_{3}$ & 0.72 & 0.85 & 0.88 \\
\hline
\end{tabular}

\subsection{Result analysis}

LINGO mathematics software was used to calculate the $\mathrm{C}^{2} \mathrm{R}$ model ${ }^{[5]}$, and the effective value $\theta_{j}(j=1,2,3)$ of DEA for each DMU was obtained, as shown in Table 4.

TABle 4.Effective values of $\mathrm{C}^{2} \mathrm{R}$ MOdel. 


\begin{tabular}{|c|c|}
\hline $\mathbf{D M U}_{\mathbf{j}}$ & $\theta_{j}$ \\
\hline $\mathrm{DMU}_{1}$ & 0.9313 \\
\hline $\mathrm{DMU}_{2}$ & 1.0000 \\
\hline $\mathrm{DMU}_{3}$ & 1.0000 \\
\hline
\end{tabular}

It can be seen that the effective value of $\mathrm{DMU}_{1}$ does not reach 1, which means the support effect of the Mode 1 is not idea. Both $\mathrm{DMU}_{2}$ and $\mathrm{DMU}_{3}$ satisfy the validity, therefore, the super-efficiency model was used to calculate these two units. The results are shown in Table 5 .

TABLE 5.EFFeCtive VALUeS OF SUPER-EFFICIENCY MODEL

\begin{tabular}{|c|c|}
\hline $\mathbf{D M U}_{\mathbf{j}}$ & $\theta^{*}{ }_{j}$ \\
\hline $\mathrm{DMU}_{2}$ & 1.8931 \\
\hline $\mathrm{DMU}_{3}$ & 1.8895 \\
\hline
\end{tabular}

Further analysis shows that if the effective value of DEA changes after an input variable is eliminated, which means that the input has an impact on the efficiency of the system. The greater the change, the greater the impact. Therefore, by eliminating the original input variables one by one and calculating the effective value of the remaining input variables, we could analyze the importance of each input to DMU, and then find the effective method to improve the efficiency of $\mathrm{DMU}_{1}$. The results are shown in Table 6 .

Table 6.EFFeCtive Value of $\mathrm{C}^{2} \mathrm{R}$ MOdel of $\mathrm{DMU}_{1}$ AFTER ELIMINATING SINGLE INPUT VARIABLE.

\begin{tabular}{|c|c|}
\hline $\begin{array}{c}\text { Eliminated } \\
\text { Variable }\end{array}$ & $\theta_{j}$ \\
\hline$x_{1}$ & 0.8668 \\
\hline$x_{2}$ & 0.9313 \\
\hline$x_{3}$ & 0.9313 \\
\hline$x_{4}$ & 0.9313 \\
\hline$x_{5}$ & 0.8907 \\
\hline$x_{6}$ & 0.9313 \\
\hline
\end{tabular}

It can be seen that after eliminating the input variables $x_{1}$ and $x_{5}$, the effective value $\theta_{j}$ of $\mathrm{DMU}_{1}$ has a great change. That is, by improving the utilization rate of personnel $\left(x_{1}\right)$ and the number of $\operatorname{ships}\left(x_{5}\right)$, the transport efficiency of Mode 1(each unit transports separately) can be promoted to a certain extent and the replenishment effect can be improved.

\section{Summary}

It is of profound significance to scientifically evaluate the existing transport mode and explore the problems in it to improve the maritime transport support capability of the islands and reefs. In this paper, the DEA model was adopted to calculate the relative efficiency of different decision-making units according to the resource input and benefit output.We made a comparatively objective comparative analysis of the three maritime transport support modes and further explored the improvement scheme.It can be seen from the results that the joint logistic support mode(Mode 2) has the highest efficiency, while the efficiency of civil-military integrated mode(Mode 3) is slightly lower, but it also has great advantages over the separate support mode(Mode 1).Therefore, joint logistic support should be given priority to, and the joint logistic department should make overall planning, and make full use of local superior resourcesto replenish the personnel stationed on the islandwhen conditions permit, so as to effectively improve the maritime transport support capacity of islands and reefs.

\section{References}

[1] Du Dong, Pang Qinghua. Modern Comprehensive Evaluation Method and Case Selection [M]. Beijing: Tsinghua University Press, 2006: 62-64.

[2] Ma zhanxin, Ma shengyun, Bao Siqin Gaowa. Data Envelopment Analysis and Application Cases [M]. Beijing : Science Press, 2013: 11-19.

[3] Lu Kai, Nie Chenglong. Research on the Determination Method of Core Support Capability [J] . Journal of Academy of Armored Force Engineering, 2016, 6 (30) : 16-20.

[4] Yang Guoliang, Liu Wenbin , Zheng Haijun . Review of Data Envelopment Analysis[J]. Journal of Systems Engineering, 2013, 6 (28) : 840-861.

[5] Hu Juhua. Super-efficiency DEA Model and Its Implementation in Lingo [J]. Journal of Jiangxi Vocational and Technical College of Electricity, 2015, 4 (29) : 58-62.

[6] He Qiang, Liu Zhong, Fan Lingyu. Evaluation of Security Programs Based on DEA in Military Railway Transportation [J]. Journal of Military Transportation University, 2015, 5 (17) : 28-31. 